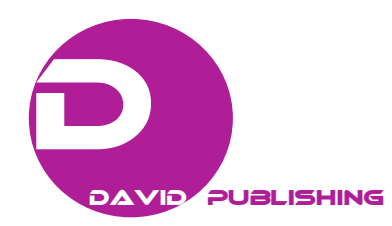

\title{
Cost Impact of Increasing Heavy Vehicle Loads on Bridges
}

\author{
Adel Elfayoumy and Nasim Uddin \\ Department of Civil, Construction and Environmental Engineering, University of Alabama at Birmingham, Birmingham 35294, USA
}

\begin{abstract}
This study aimed to investigate the cost impact of meeting the increase in freight demand by doubling the truck weight (AS1), doubling the traffic volume (AS2), or legalizing a new-proposed-truck of 97-kip weight instead of the currently legal 80-kip truck (AS3). The State of Michigan's average daily traffic database of year 2001 has been used as a case study. The study was applied only on the very common US Bridge with RC (reinforced concrete) deck over steel girder. Sampling criteria also includes the age of the bridges. The study covered the four-cost-impact categories provided by the NCHRP (National Cooperative Research Program). The current truck weight and double traffic volume (AS2) show the best scenario to meet the increase in freight demand. However, doubling the truck weight with the current traffic volume (AS1) was the worst scenario. The use of the proposed 97-kip truck with the current traffic volume (AS3) compromises both, meeting the increase in freight demand and the cost impact.
\end{abstract}

Key words: Increasing heavy vehicle load, cost impact, LCC (life-cycle cost).

\section{Introduction}

The use of heavy vehicles is the backbone of freight shipment and the corner stone of economic success in the United States. National projections predict that freight shipments will be doubled in the next 10 years. This increase in freight demand must be accommodated by increasing the trucks' number, the weight, or both. It is quite obvious that increasing the number of heavy vehicles or their weight will inversely affect the bridge lifespan. Thus, congestion problem, due to increased number of heavy vehicles, must be addressed. Moreover, additional repetitive loading may cause fatigue cracking in these bridge superstructures and limit their service lives.

All the heavy vehicles configurations directly affect the safe service life of highway bridge superstructures. Generally, deterioration occurs in the deck and superstructure elements including but not limited to girders, joints and diaphragm joints. The occurred damage is mainly a function of construction material

Corresponding author: Adel Elfayoumy, Ph.D., research assistant, research fields: bridge engineering, increasing heavy vehicle load, cost impact and LCC (life-cycle cost). E-mail: afayoumy@uab.edu. and the heavy vehicles' gross weight. Meeting the increasing freight demand means increasing the number of heavy vehicles and/or the total weight of the trucks. Bridge costs, associated with both solutions, are the result of the accelerated maintenance, rehabilitation, or replacement work that is required to keep the structures at an acceptable level of service [1].

The bridge cost and the whole life cost are directly impacted upon by the change of the current traffic situation. Increasing the number and/or weight of heavy vehicles impacts the costs. These costs are calculated using the NCHRP (National Cooperative Highway Research Program) Report 495 [2]. Cost impact, associated with different possible remedy actions, was calculated. This cost impact was used to calculate the bridge's cost over the span of PP (planning period) of interest.

\section{Literature Review}

LCCA (life-cycle cost analysis) is a tool that helps the transportation agencies in assets estimation and management. However, the fundamentals of the LCCA were started long time ago, while the attention given to this tool was increased in the lately United States. 
A long-term investment that requires regular and periodic inspection and maintenance is considered for bridges. It needs retrofitting in some cases and replacement in other rare cases. The whole life-cycle cost of bridges includes not only the construction cost, but also the expected future activities' cost that should be presented in a cash flow diagram, as shown in Fig. 1. The LCCA helps to maximize the effectiveness of the limited allocated maintenance budget and make a decision with these computed future expenses. Maintenance activities and alternatives vary based on the characteristic of distress, allocated budget and local practices of every state. Different alternatives' costs may be classified by two main partners of the bridge - the agency and the user [3].

Estimating the cost impact for a specific scenario of truck weight limit change needs to determine the PP (planning period). This period defines the time span during which the cost impact is considered effective. It is recommended that the period could be consistent with the agency's planning period, so that parameters for projecting future data would be readily available. These parameters may include discount rate, traffic growth rate and expected funding levels. A 20-year period may be used as the default value for PP, if more specific information is not available to help while a project needs to be put into a more realistic period [1].

\section{Cost Impact Estimating Methodology and Approach}

As per the NCHRP Report 495, four cost-impact categories are covered in this research: (1) Category 1, fatigue of existing steel bridges; (2) Category 2, fatigue of existing RC (reinforced concrete) decks; (3) Category 3, deficiency due to overstress for existing bridges; (4) Category 4, deficiency due to overstress for new bridges [2]. It should be noted that there are also other categories that contribute to the cost impact as a result of truck weight limit changes, such as the fatigue failure of steel expansion joints. However, these listed costs could be considered less significant relative to those in the four main categories.

In this research, a software module developed by NCHRP, named "Carris", was utilized to estimate the cost increment of a bridge network due to a change in truck weight limits. Truck weight collectively refers to GVW (gross vehicle weight), axle weights and axle spacing.
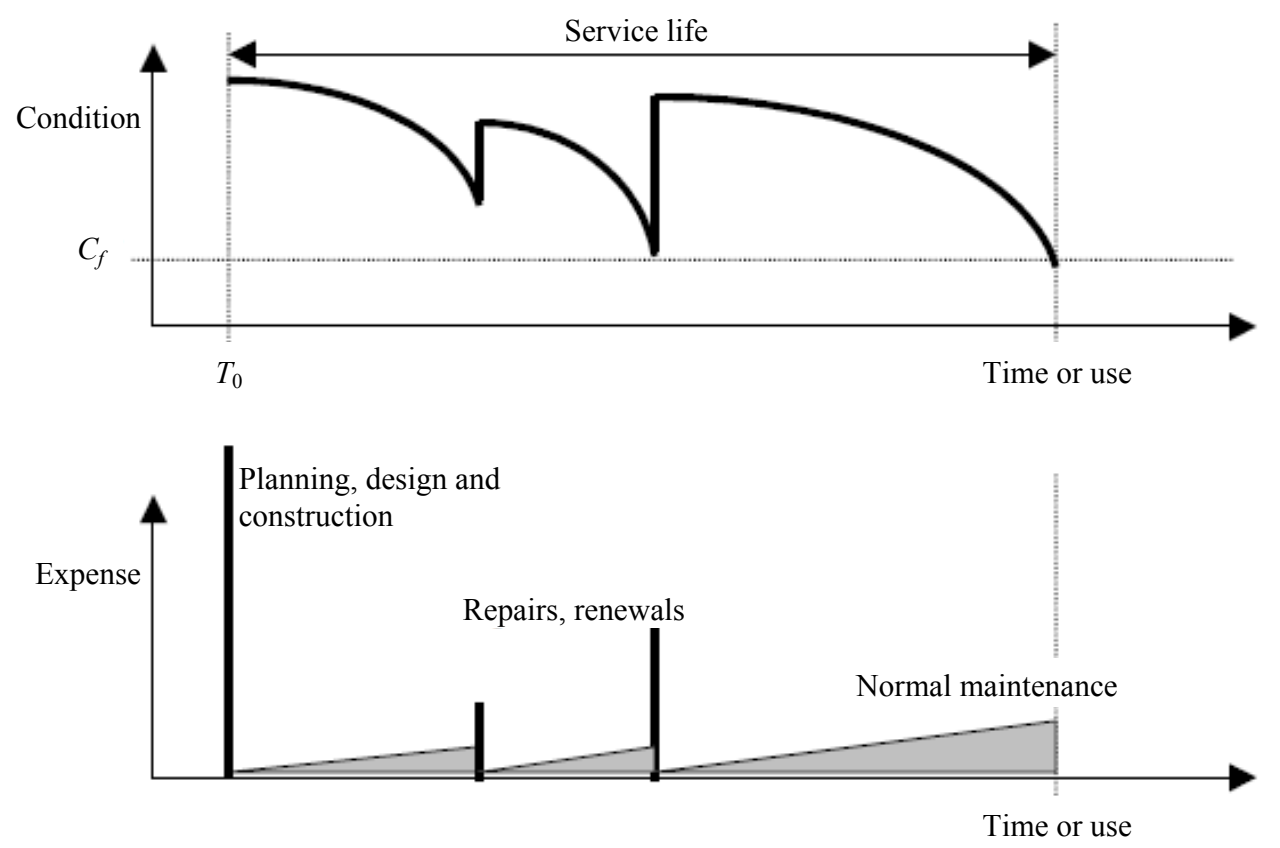

Fig. 1 Expenses accompanying the life cycle over the SL (service life) [3]. 


\section{Case Study: Truck Weight Limit Change Cost Impact}

To investigate the bridge cost impact of doubling the current traffic load and/or doubling the traffic volume to meet the increase in freight demand, the State of Michigan Average Daily Traffic Database for year 2001 has been used as a case study [2]. The database shows the condition of 12,400 bridges in Michigan in the year 2001. These data were classified based on the functional classes provided by FHWA (Federal Highway Administration). Fig. 2 shows the most common types of vehicles which are listed in the database. The study was applied to selective bridges based on a stratified random sampling approach. For this case study, the design truck load was HS25 truck, not HL93, as shown in Fig. 3. The Carris program was utilized to calculate the cost impact of both scenarios
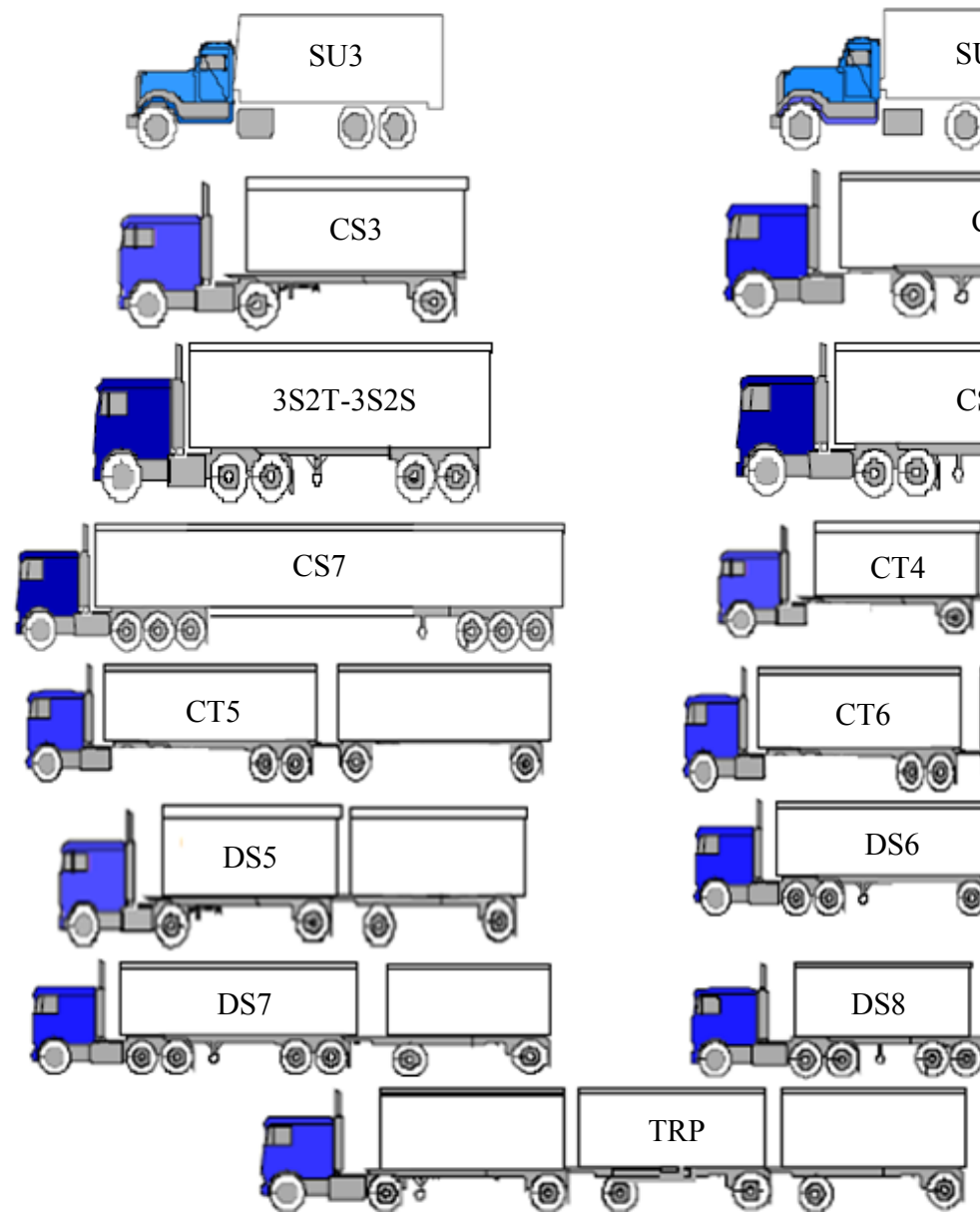

Fig. 2 Most common types of vehicle at the State of Michigan, 2001 [2]. on the four expected cost-impact categories [2].

\subsection{General Factors and Parameters}

In general, some factors and parameters need to be predefined as defaults in order to run the program, such as customary units, discount rate of cost, annual growth rate and the truck traffic percentage. Thus, the customary unit was set equal to 1 to use the US units, and respectively, the discount rate in cost calculation and the annual growth $(g)$ was set equal to $0.03(3 \%)$. The entire given inventory data represents the $\mathrm{BC}$ (base case) of the ADT (average daily traffic), so the truck percentage was set equal to 5 to calculate the ADTT (average daily truck traffic). To cover the dynamic effect of truck, the impact factor $(I)$ was set to 1.3. For fatigue calculation of the RC deck, the tire print area (length and width, respectively) was set to $80 \mathrm{in}$. and 20 in.
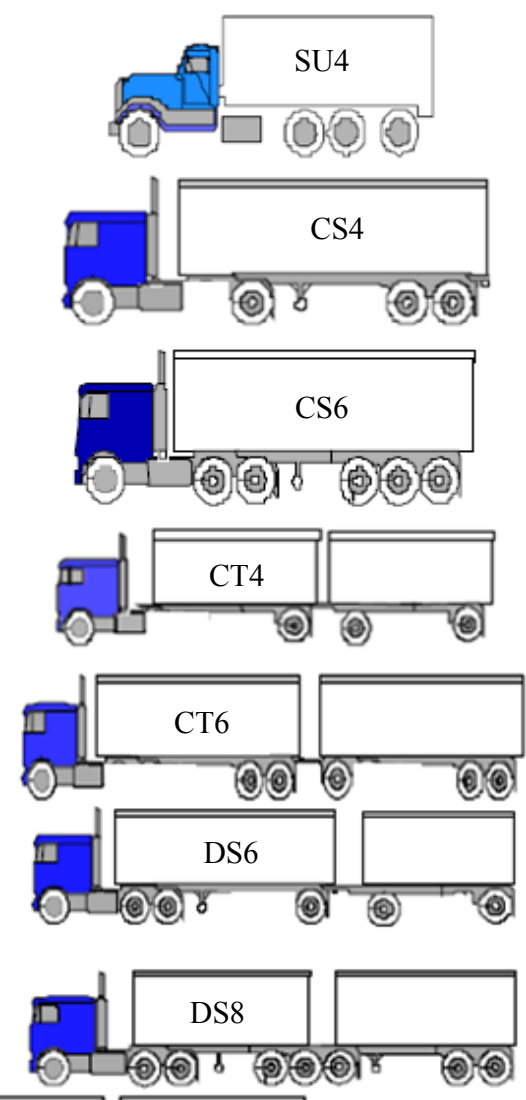

TRP 


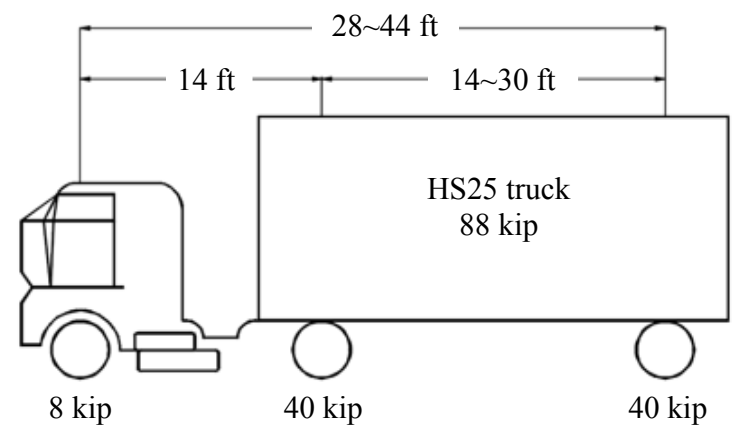

Fig. 3 HS25 and HL93 trucks configurations.

For the State of Michigan, the cost rates and values for different cost-impact categories were set, as shown in Fig. 4. It illustrates the cost associated with each category and the expected remedy action under each cost-impact category. The fatigue category $\mathrm{E}$ and E-prime in the block "fatigue detail types and repair costs" represent costs for the welding type of connection [4].

\subsection{Typical Truck Characteristics}

Figs. 5 and 6, respectively, show samples of the TWH (truck weight histogram) of the database for rural and urban functional classes. That illustrates that the 3S2T truck type ( $80 \mathrm{kip}$ ) is the most prevalent-heaviest truck. Thus, primary focus was placed on this truck in both scenarios to meet the increase in freight demand. Fig. 7 illustrates the 3S2T truck configurations.

\subsection{Sampling and Stratifying}

The inventory data of the State of Michigan, which represent the traffic for year 2001, were sampled to represent the four cost-impact categories.

\subsubsection{Category 1}

Only the steel bridges of 50 years old and less were considered in the Category 1 cost-impact study. These preconditions result in the selection of only 5,672 bridges out of the total number of state bridges, and of these bridges, only 14 steel bridges with reinforced concrete deck were selected, randomly.

\subsubsection{Category 2}

Michigan is one of the states that use a large amount of salt for deicing. Salt accelerates the corrosion of

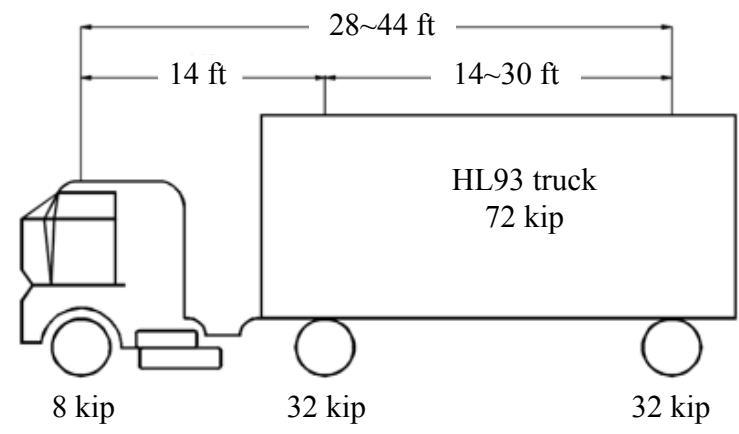

steel reinforcement and RC deck deterioration. This approach does not account for the effect of steel corrosion on the RC deck fatigue. The same 14 bridges in Category 1 were selected.

\subsubsection{Category 3}

All Michigan's bridges were considered. The operating load rating was set equal to 1 which means that all the load ratings are greater than or equal to 1 and are taken as adequate ratings with no deficiencies and no respond actions. These conditions call for all bridges in the state to be considered.

\subsubsection{Category 4}

This category covers the cost impact due to the change of the design criteria for the new bridges. The analysis for this category needs to identify a sample of new bridges representing future new bridges. This can be done by defining a year that represents a base year, so all bridges built in that year or later will be defined as new bridges. This is based on the assumption that the type and size of new bridges to be built in the next 20 years will be similar to those built in recent years [2]. The base year was set as 2000 . This means that all the bridges built during that base year would act as an estimate of annual bridge construction including all the associated costs.

\subsection{Current Traffic Conditions-BC (Base Case)}

In this case, the current traffic conditions were maintained with no changes to check the current status of the being considered bridges and decks. Based on the $\mathrm{BC}$ conditions, only Category 3 was affected. In case of applying the operating conditions, only one 
Effect of Truck Weight on Bridge Network Costs - NCHRP 12-51

\title{
Action Costs and Factors
}

\author{
Background Data
}

New bridge construction cost per square meter

Category 1 fixed cost per bridge

929.2

\begin{tabular}{r|}
\hline 929.2 \\
\hline 1000 \\
\hline
\end{tabular}

\begin{tabular}{|llr|rrr|}
\hline Fatigue Detail Types and Repair Costs & & \multicolumn{3}{l|}{ Cost Impact Factor } \\
\hline \multicolumn{2}{|c|}{ Type Name } & Cost each & Const & Variable & Bend (m) \\
\hline D & None & 0 & 0 & 0 \\
B1 & Welds of partial-length coverplates & 775 & 0.71 & 0.0612 & 15.24 \\
B4 & Term. of welded long. Web stiffeners & 360 & 1 & 0 & 0 \\
B5a & Welded long. conn. plate (top of flange) & 3415 & 0.75 & 0.0496 & 30.49 \\
B5b & Welded long. conn. plate (bottom of flange) & 4015 & 0.75 & 0.0496 & 30.49 \\
Z & Other & 0 & 0 & 0 & 0 \\
\hline
\end{tabular}

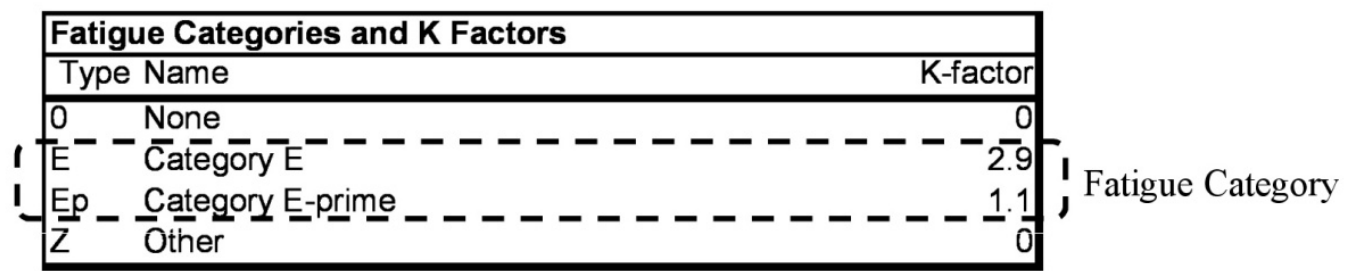

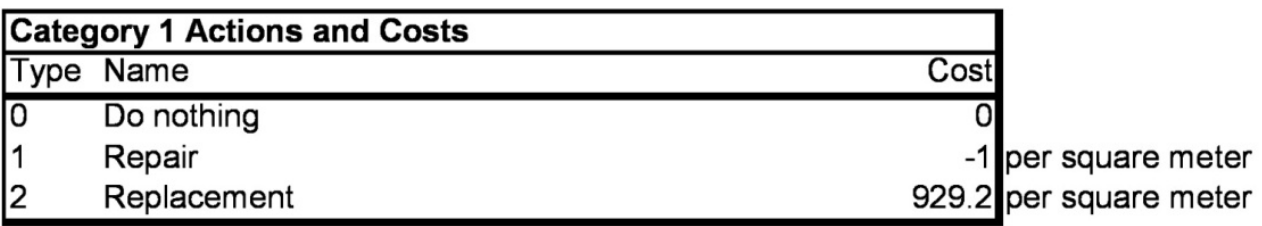

\begin{tabular}{|c|c|c|c|}
\hline \multicolumn{3}{|c|}{ Category 2 Actions and Costs } & \\
\hline Type & Name & Cost & \\
\hline 0 & Do nothing & 0 & \\
\hline 1 & Patching \& conc overlay & 200 & per square meter \\
\hline 2 & Concrete overlay & 204.51 & per square meter \\
\hline 3 & Patching and AC overlay & 150 & per square meter \\
\hline 4 & AC overlay & 120 & per square meter \\
\hline 5 & Patching \& deck replace & 300 & per square meter \\
\hline
\end{tabular}

\begin{tabular}{|c|c|c|c|}
\hline \multicolumn{3}{|c|}{ Category 3 Actions and Costs } & \multirow{6}{*}{$\begin{array}{l}\text { per bridge } \\
\text { per square meter } \\
\text { per square meter }\end{array}$} \\
\hline$\overline{\text { Type }}$ & Name & Cost & \\
\hline \multirow{4}{*}{$\begin{array}{l}0 \\
1 \\
2 \\
5\end{array}$} & Do nothing & 0 & \\
\hline & Enforcement only & 4656 & \\
\hline & Strengthening & 200 & \\
\hline & Replacement & 929.2 & \\
\hline & Enforcement annual cost & 116400 & per enforcement crew per year \\
\hline & Number of bridges covered by one crew & 500 & bridges per crew \\
\hline & Planning period & 20 & years \\
\hline & Present value & 4656 & per bridge total \\
\hline
\end{tabular}

Fig. 4 Cost associated with the proposed remedy actions in each category. 


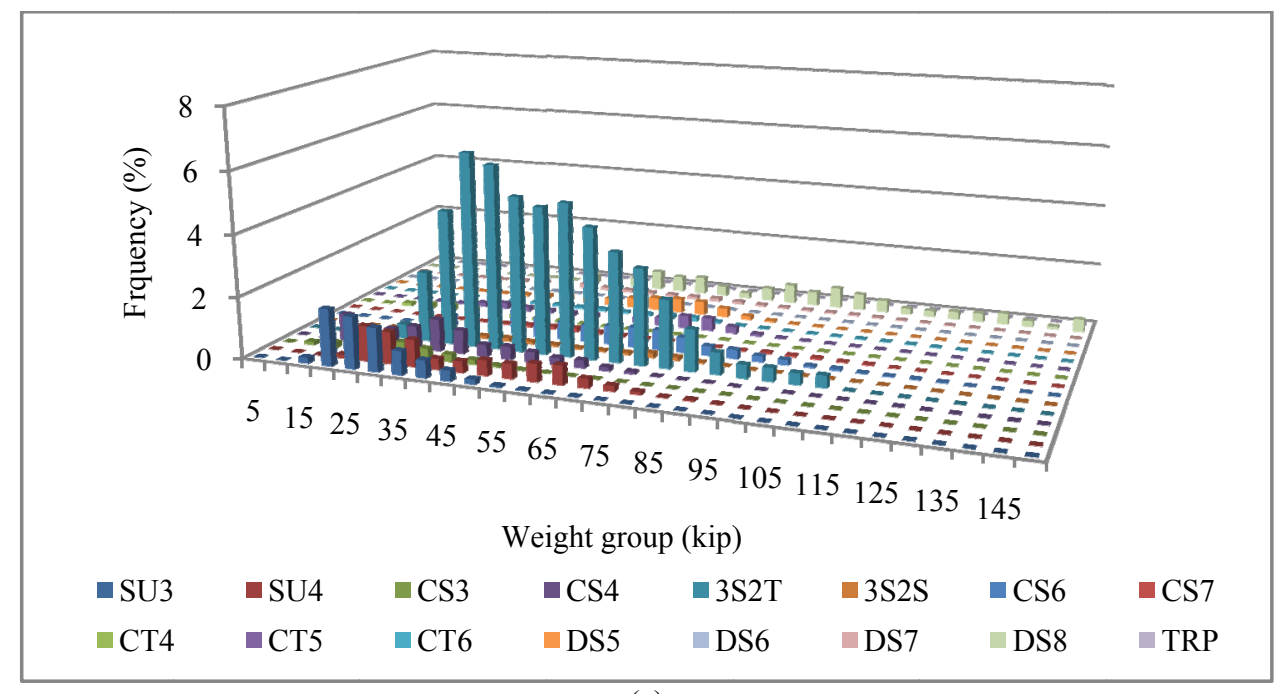

(a)

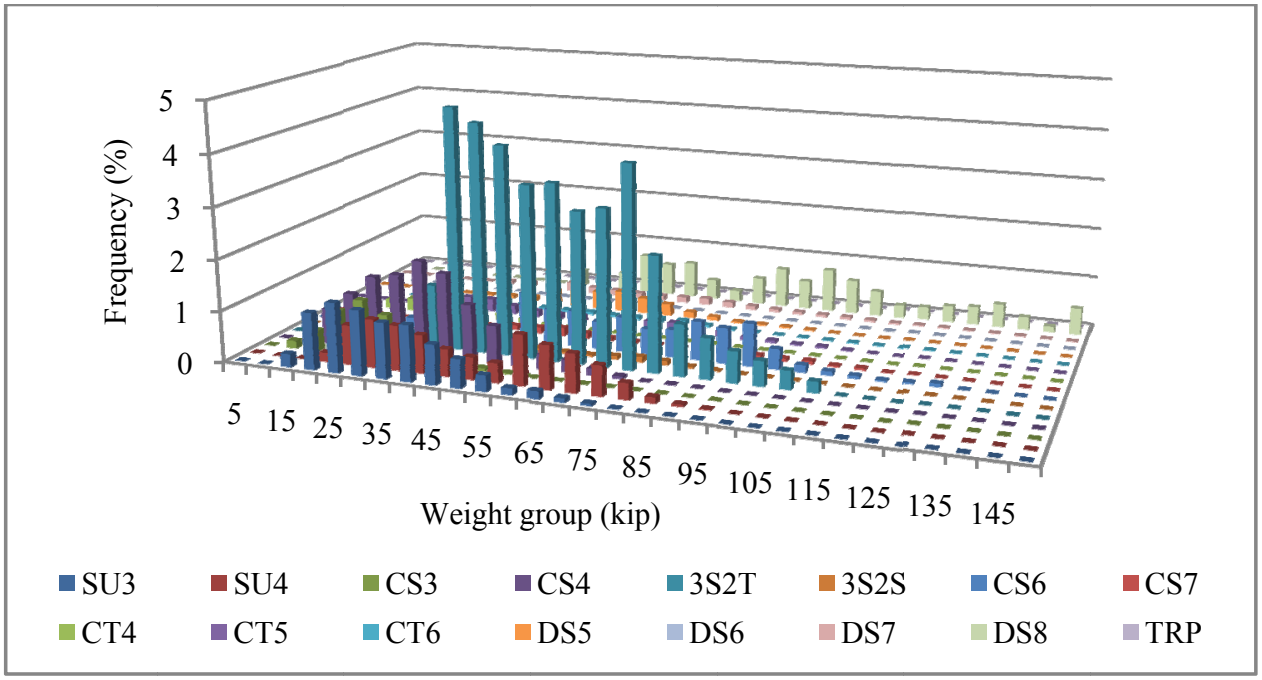

(b)

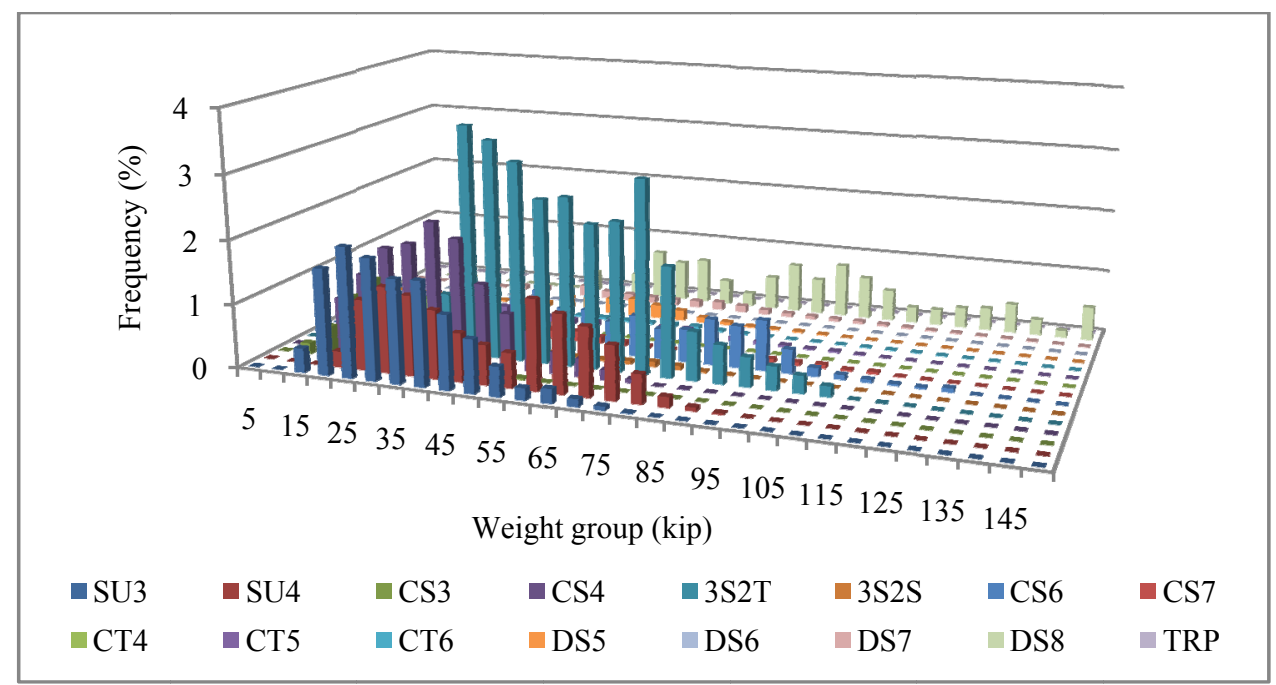

(c)

Fig. 5 BC TWH for some rural functional classes: (a) rural interstate; (b) rural other principal arterial; (c) rural minor arterial. 


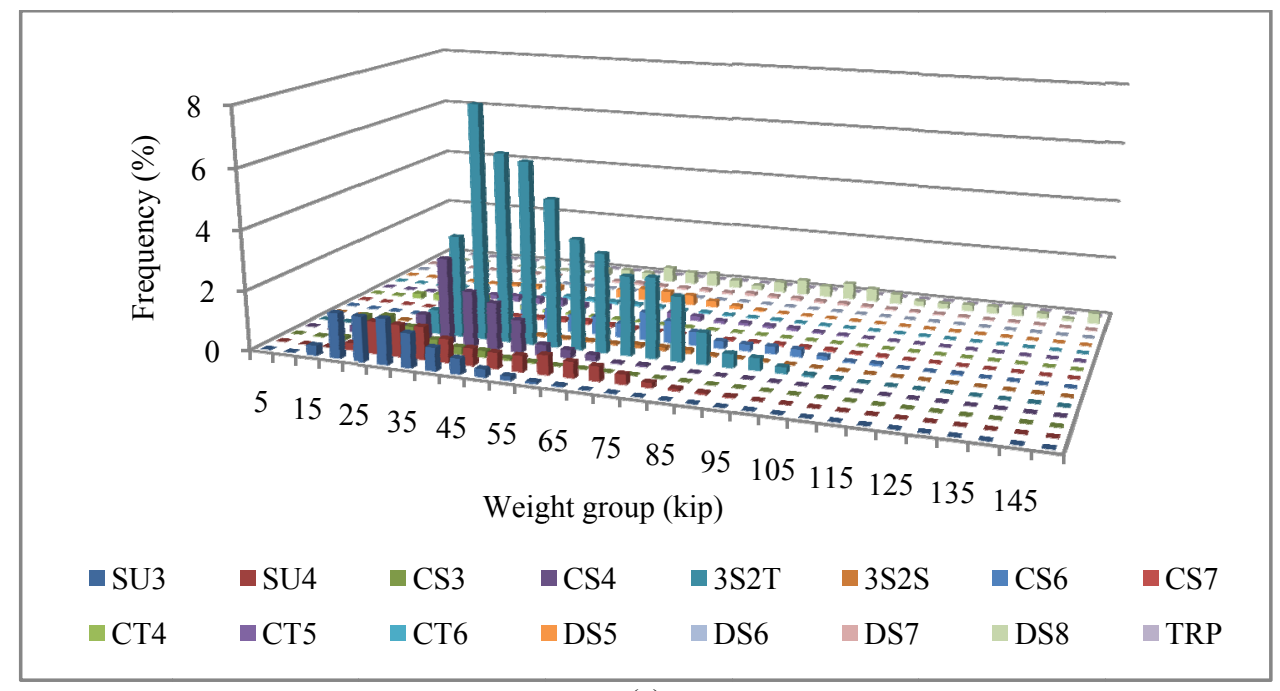

(a)

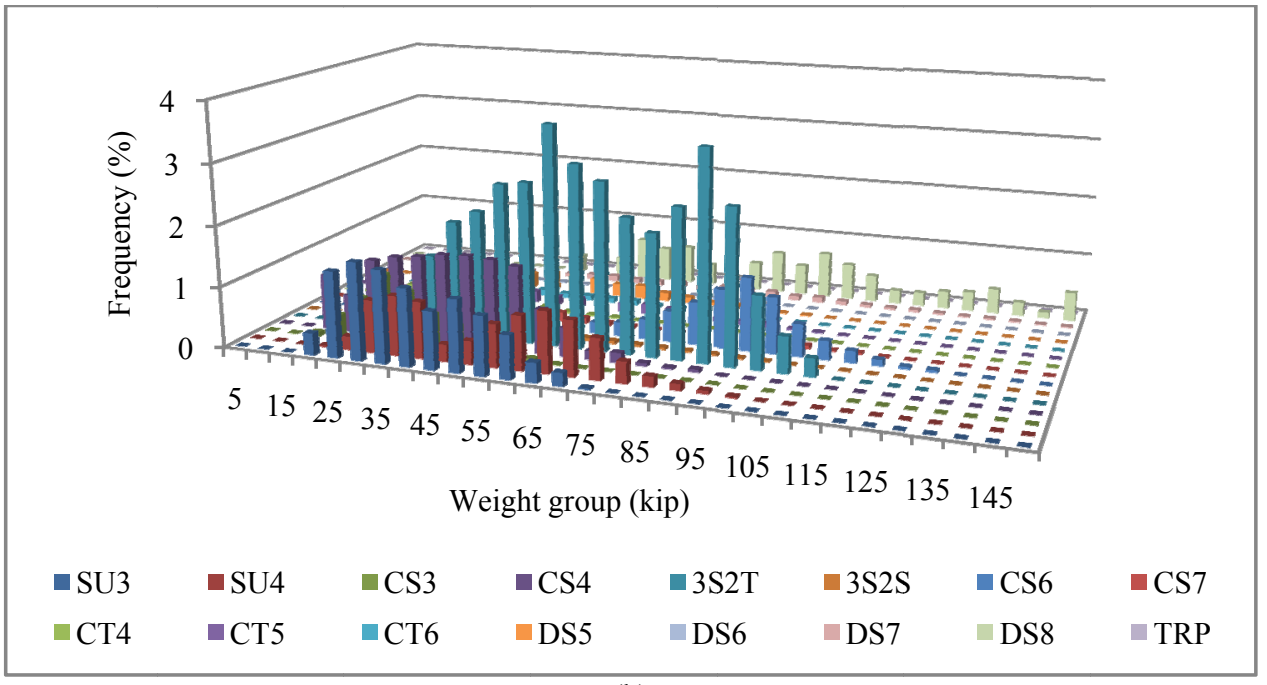

(b)

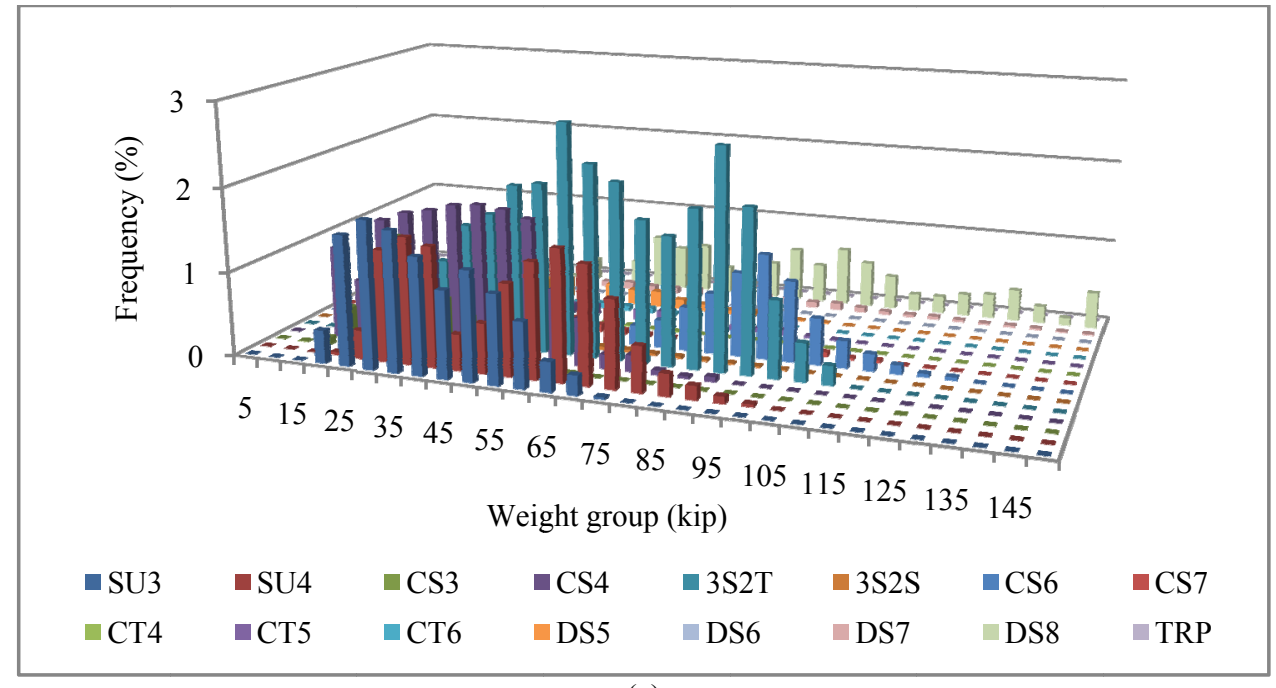

(c)

Fig. 6 BC TWH for some urban functional classes: (a) urban interstate; (b) urban freeway/express way; (c) urban other principal. 


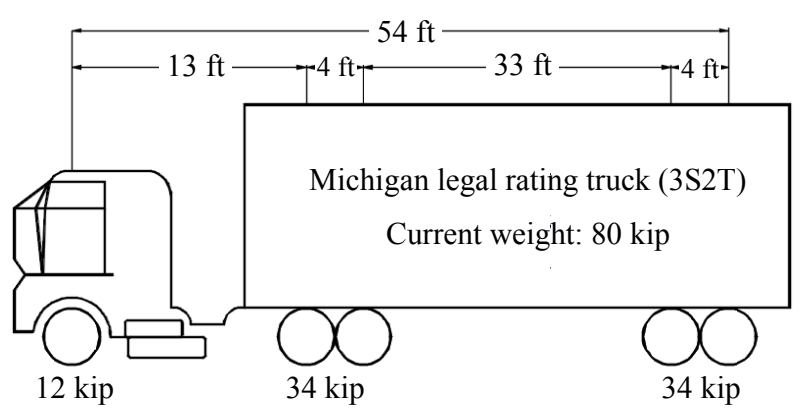

Fig. 7 Michigan most prevalent truck.

Table 1 Cost impact for different respond actions.

\begin{tabular}{llll}
\hline \multirow{2}{*}{$\begin{array}{l}\text { Cost-impact } \\
\text { category }\end{array}$} & \multicolumn{3}{c}{ Cost-impact (\$) responding actions } \\
\cline { 2 - 4 } & Posting & Strengthening & Replacement \\
\hline Category 3 & 4,656 & 75,040 & 348,636 \\
\hline
\end{tabular}

bridge was affected. Table 1 shows the cost associated with different respond actions.

\subsection{DTW (Double Tuck Weight)—AS1 (Alternative Scenario 1)}

The cost impact was calculated during a planning period of 20 years for all the proposed response (remedy) actions for each cost impact category. The calculation included increasing (doubling) the prevalent truck GVW (3S2T) from 80 kip to 160 kip. Because of no changes in the truck traffic volume, the TWH was similar to that of the current traffic condition. The current traffic condition case was considered as the base case.

In this case AS1, nine bridges in Category 1, two bridges in Category 2 and 100 bridges in Category 3 were affected. For Category 4, seven bridges were expected to be affected. Fig. 8 shows the cost impact of different cost-impact categories based on the proposed responding action of each cost impact category, as shown in Fig. 4.

\subsection{DTV (Double Traffic Volume - AS2 (Alternative Scenario 2)}

The second alternative scenario AS2 to meet the increase in freight demand is to increase (double) the number of prevalent truck (3S2T). In this case AS2, the cost impact was estimated under the same sampling criteria as AS1. The AS2 TWH samples are illustrated in Figs. 9 and 10. In this case, the TWH is changed due to the doubling of the most frequent truck numbers

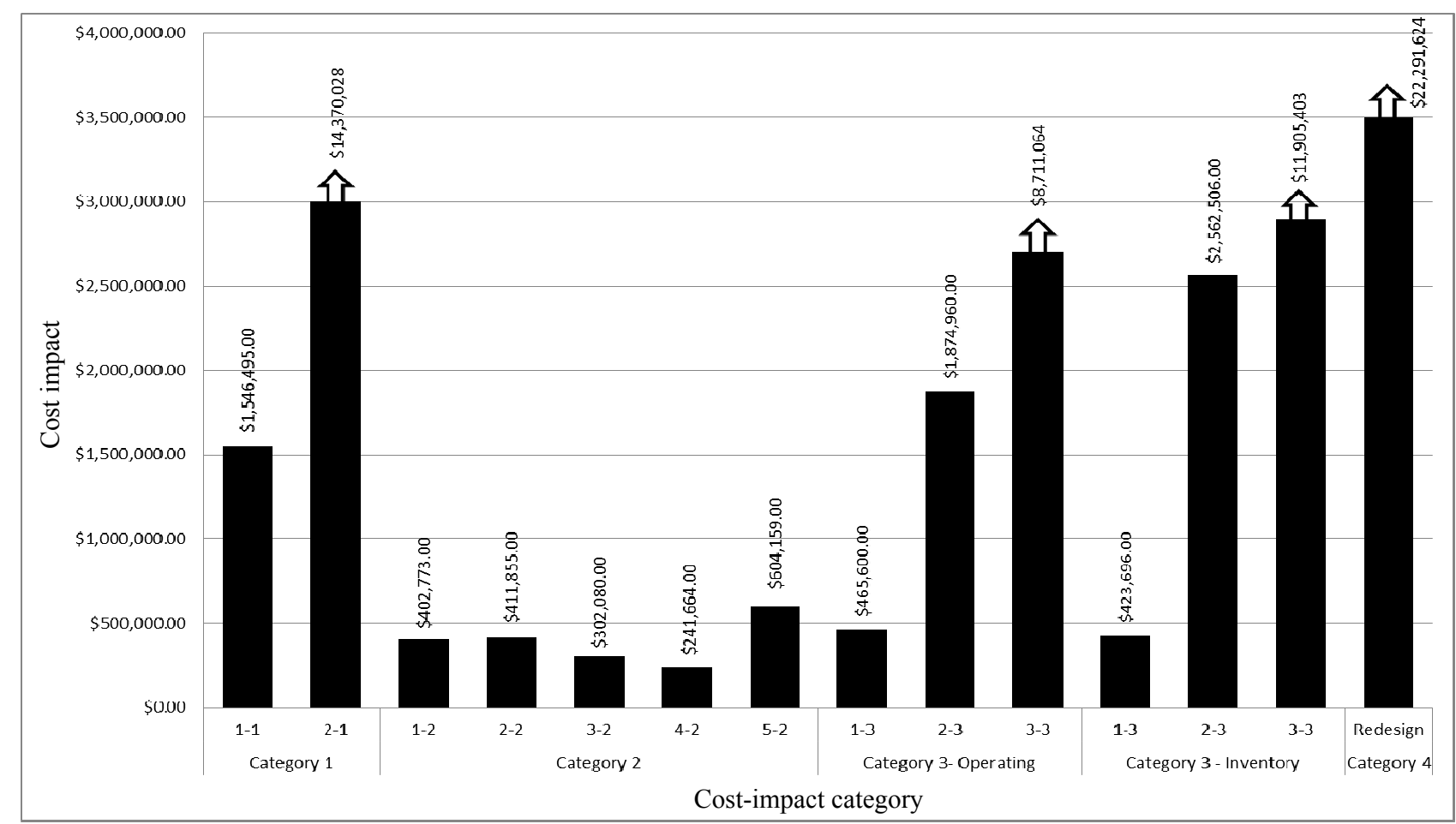

Fig. 8 Cost-impact categories with different responding action in AS1. 


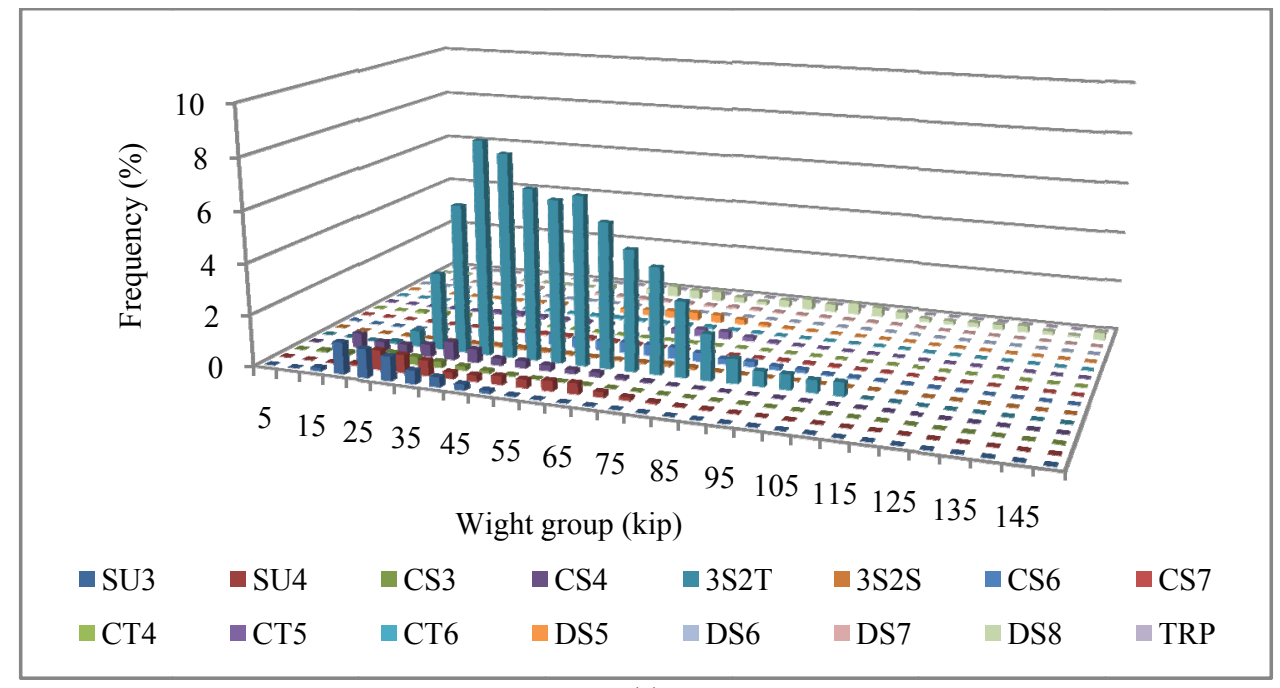

(a)

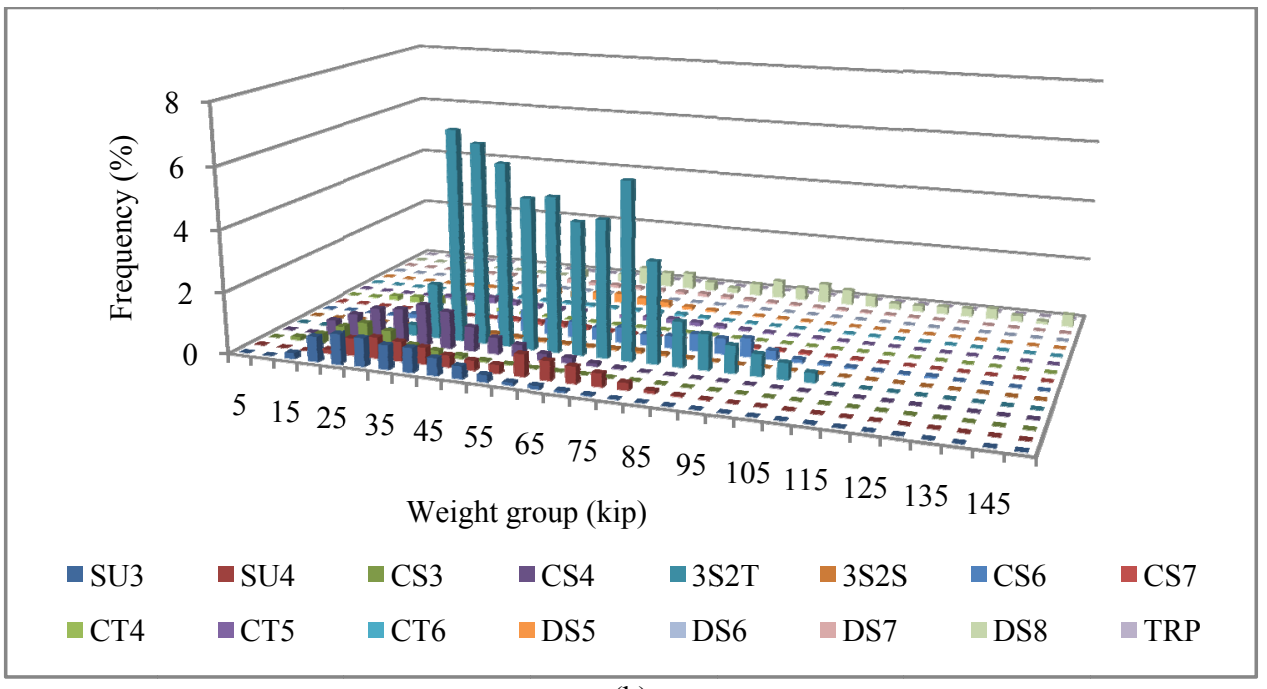

(b)

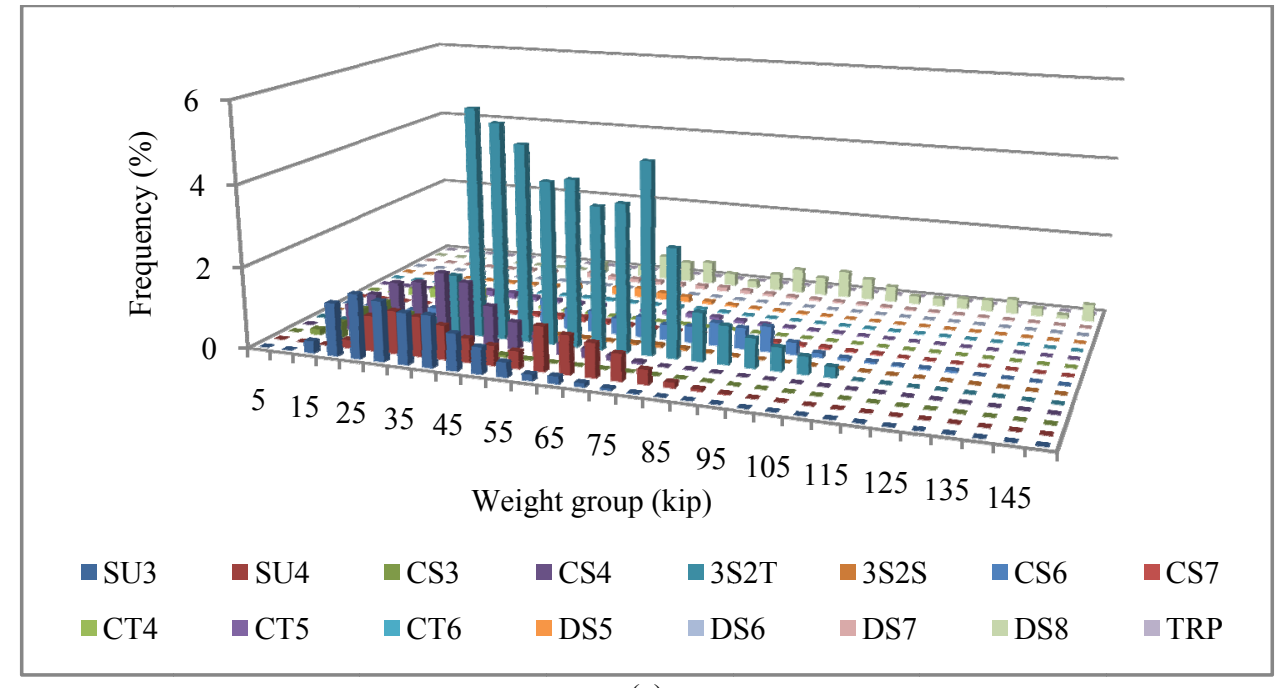

(c)

Fig. 9 AS2 TWH for some rural functional classes: (a) rural interstate; (b) rural other principal arterial; (c) rural minor arterial. 


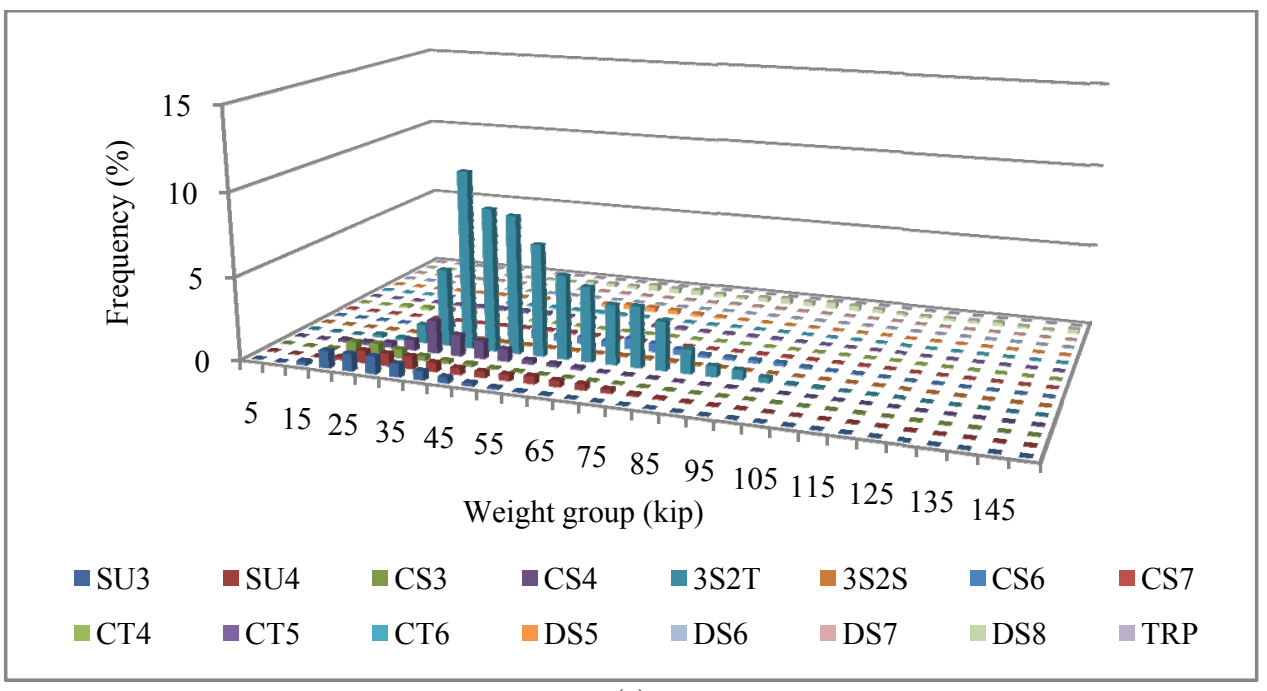

(a)

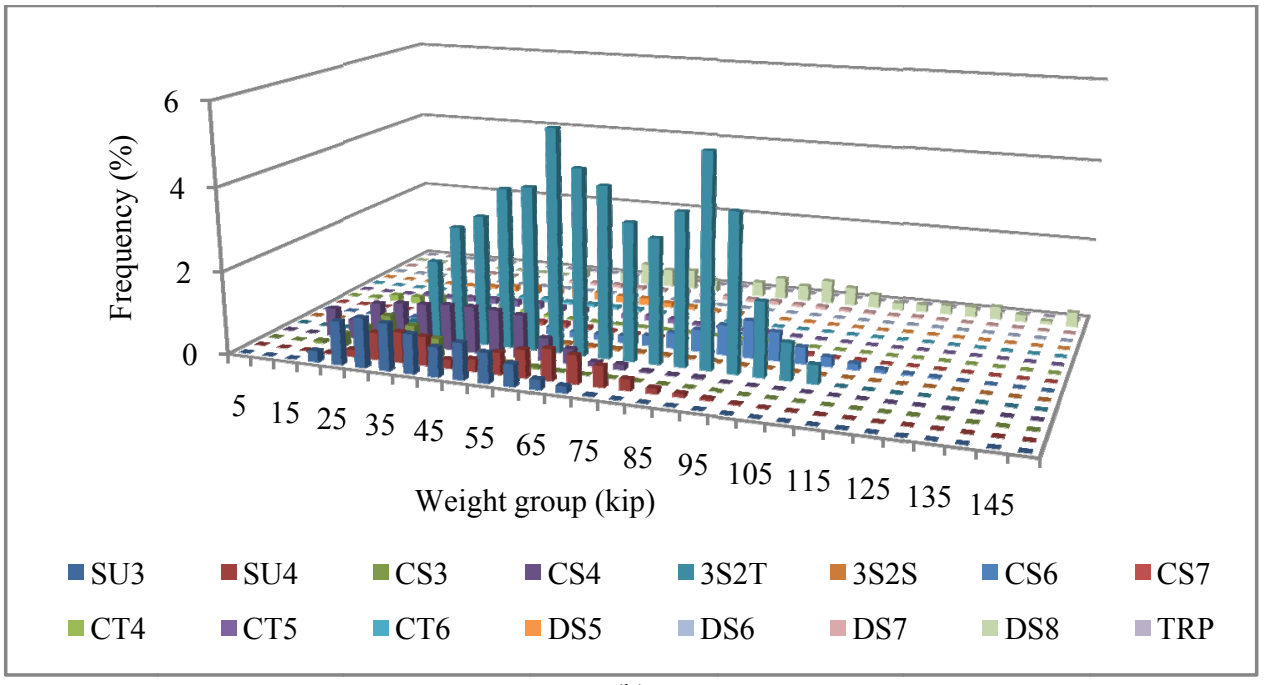

(b)

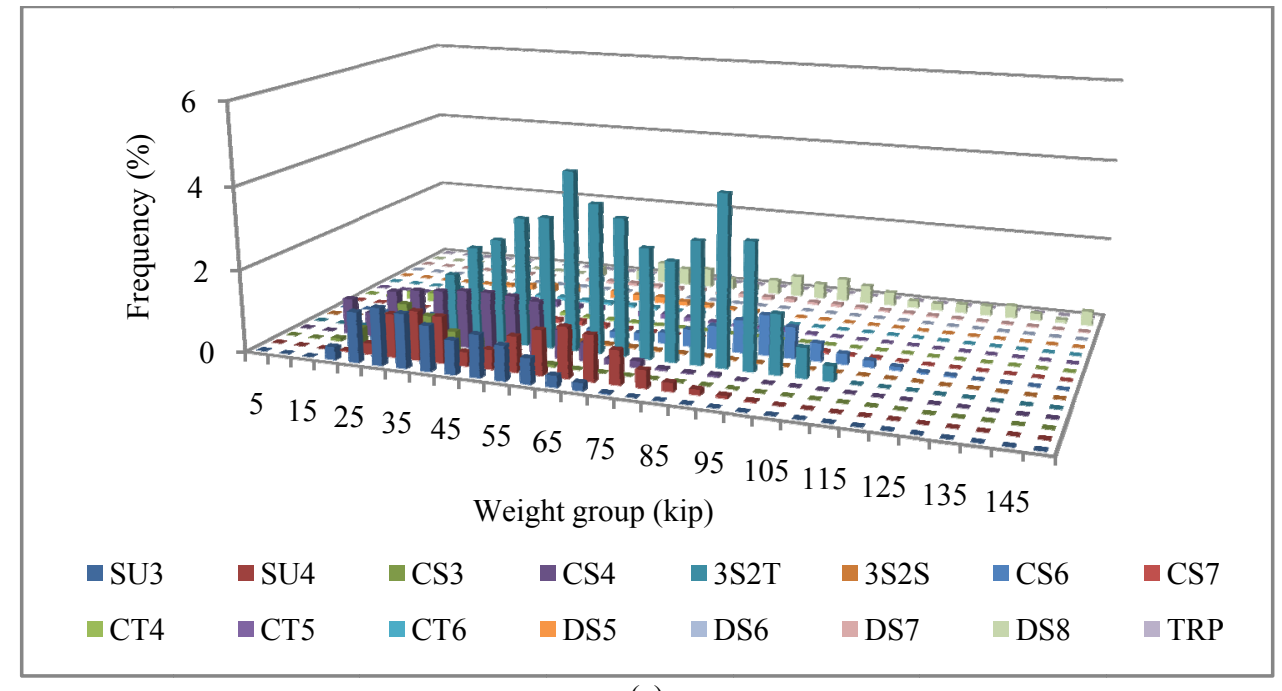

(c)

Fig. 10 AS2 TWH for some urban functional classes: (a) urban interstate; (b) urban freeway/express way; (c) urban other principal). 


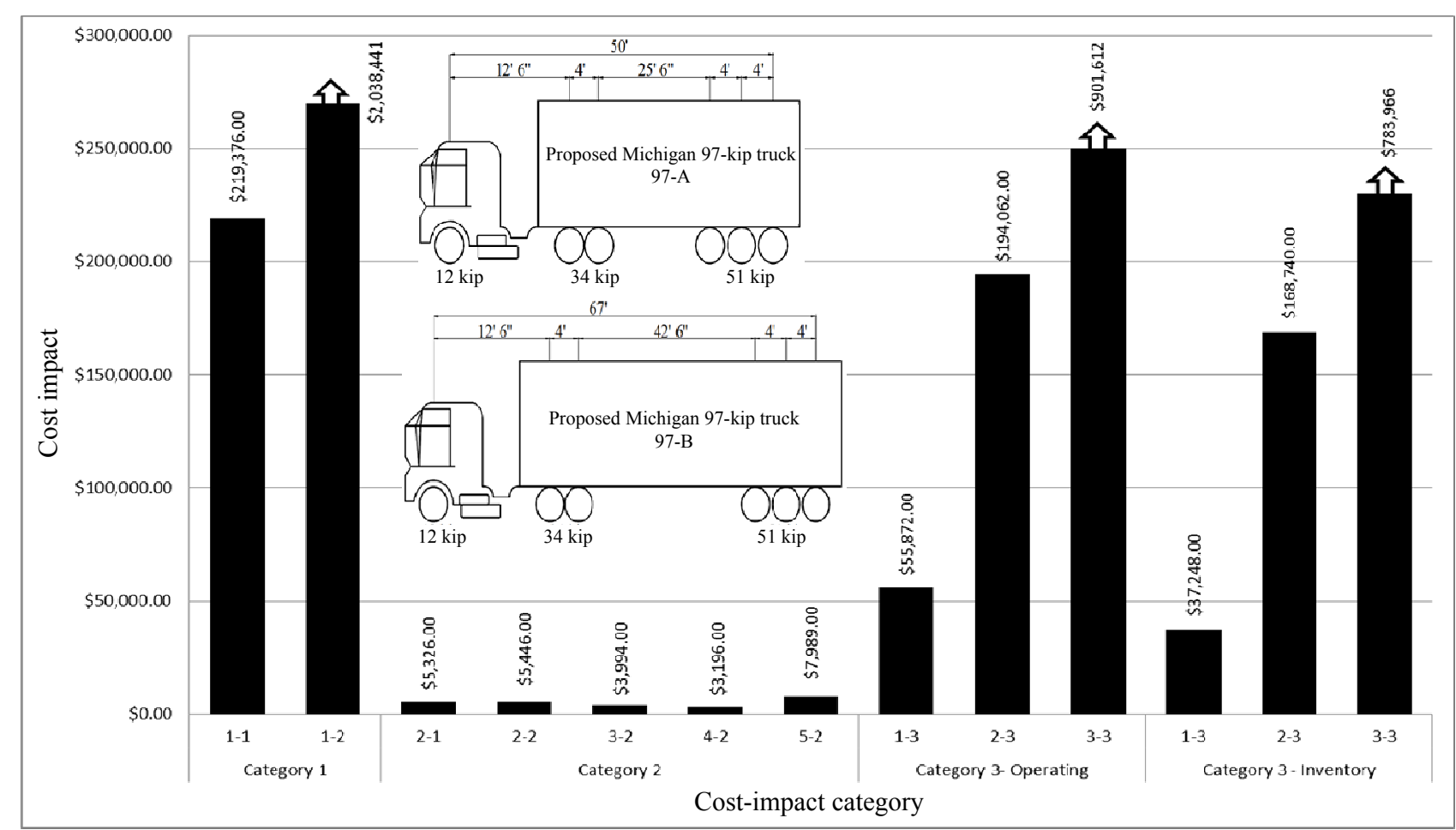

Fig. 11 Configurations of the proposed 97-kip trucks and cost-impact categories in AS3.

with no changes in the GVW.

With no changes in the GVW, the same bridge affected in BC was affected in AS2 with the same cost impact, as shown in Table 1.

\subsection{Proposed 97-Kip Truck-AS3 (Alternative Scenario 3)}

Another alternative scenario was proposed to meet the increase in freight demand. This scenario replaces the five-axle truck of 80 kip (3S2T and $3 \mathrm{~S} 2 \mathrm{~S}$ ) by a proposed six-axle truck of 97 kip (97-A and 97-B). These configurations represent the lower and upper bounds for the total length of these trucks. The current traffic volume and the TWH of both $3 \mathrm{~S} 2 \mathrm{~T}$ and $3 \mathrm{~S} 2 \mathrm{~S}$ trucks are used to predict AS3 TWH. The proposed truck configurations and the associated cost impact is shown in Fig. 11.

\section{Results and Discussion}

The aim was to provide a bridge network maintenance tool based on the cost impact. A cost-impact study was performed for the inventory database of year 2001 of the State of Michigan. The current weight of legal rating truck was assumed as the BC. Different AS (alternative scenarios), double legal truck weight (AS1), double traffic volume (AS2) and a Michigan proposed 97-kip truck (AS3), are studied. The cost-impact categories proposed by NCHRP Report 495 were applied to the study.

For the study, 14 numbers of bridges were selected randomly based on certain criteria for Category 1 (fatigue of steel bridges) and Category 2 (fatigue of RC deck). For Category 3 (deficiency due to overstress of existing bridges), all the state's bridges network was examined. For Category 4 (deficiency due to overstress of new bridges), the used program detected 14 number of bridges which are expected to be designed and built in the predefined PP (20 years).

In BC (current truck weight and current traffic volume) and AS2 (current truck weight and double traffic volume), only one bridge was affected in cost-impact Category 3. The total cost-impact ranges between $\$ 4,656$ and $\$ 348,636$ based on the selected response action. 
In AS2 (double truck weight and current traffic volume), 5, 14, 100 and 12 numbers of bridges were affected in Category 1, Category 2, Category 3 and Category 4, respectively. The total cost impact of these categories ranges between $\$ 24,545,383$ and $\$ 45,784,571$. In AS3 (use proposed 97-kip truck), 5, 14 and 12 numbers of bridges were affected in Category 1 , Category 2 and Category 3, respectively. The total cost impact ranges between $\$ 278,444$ and \$2,948,042 .

\section{Conclusion}

The cost impact range depends on the selected respond action to maintain the bridge functionality. In terms of cost impact, the AS2 (current truck weight and double traffic volume) shows the best scenario to meet the increase in freight demand. But, AS1 (double the truck weight and the current traffic volume) was the worst scenario. The use of the proposed 97-kip truck with the AS3 (current traffic volume) compromises both, meeting the increase in freight demand and the cost impact.

\section{Acknowledgments}

The authors gratefully acknowledge funding and support provided by NSF (National Science Foundation) (CMMI-1100742) and NCTSPM (National Centre for Transportation Systems Productivity and Management).

\section{References}

[1] Sivakumar, B., Ghosn, M., and Moses, F. 2011. Protocols for Collecting and Using Traffic Data in Bridge Design. Vol. 683. Washington, D.C.: Transportation Research Board.

[2] Fu, G., Feng, J., Dekelbab, W., Moses, F., Cohen, H., Mertz, D., and Thompson, P. 2003. Effect of Truck Weight on Bridge Network Costs. NCHRP (National Cooperative Highway Research Program) Report 495. Transportation Research Board, Washington, D.C., USA.

[3] Hawk, H. 2003. Bridge Life-Cycle Cost Analysis. NCHRP (National Cooperative Highway Research Program) Report 483. Transportation Research Board, Washington, D.C., USA.

[4] Gongkang, F., Thompson, P. D., Hang, J., and Dekelbab W. 2003. "Users Manual for Carris." In NCHRP 12-51 Users Manual. Washington, D.C.: NCHRP. 